\title{
Mass immunization and COVID-19: the need for continued primary health care
}

Rahim Badrfam ${ }^{1}$ and Atefeh Zandifar ${ }^{2}$

${ }^{1}$ Department of Psychiatry, Roozbeh Hospital, School of Medicine, Tehran University of Medical Sciences, Tehran, Islamic Republic of Iran. ${ }^{2}$ Social Determinants of Health Research Center, Alborz University of Medical Sciences, Karaj, Islamic Republic of Iran (Correspondence to: Atefeh Zandifar: zandifaratefe@gmail.com).

Citation: Badrfam R; Zandifar A. Mass immunization and COVID-19: the need for continued primary health care. East Mediterr Health J. 2021;27(3):312313. https://doi.org/10.26719/2021.27.3.312

Received: 04/12/20; accepted: 04/03/21

Copyright @ World Health Organization (WHO) 2021. Open Access. Some rights reserved. This work is available under the CC BY-NC-SA 3.0 IGO license (https://creativecommons.org/licenses/by-nc-sa/3.o/igo).

Sir,

Given the continuing global health emergency conditions due to COVID-19 and the need to pay attention to all public health matters, the WHO Director General stressed the Organization's efforts to continue providing services in various areas of primary health care, including vaccination (1). According to the UNICEF Regional Director for the Middle East and North Africa, while the fight against COVID-19 continues the vaccination programme for children has been problematic in some countries for a variety of reasons. Thus, in the recent past, one in five children (about 10 million people) under the age of five and about 4.5 million children under the age of 15 have not received polio and measles vaccinations, respectively (2). In addition, with the global spread of COVID-19 leading to the disruption of routine vaccination efforts, 80 million children under the age of one are at risk from diseases such as diphtheria, measles and polio (3). Recent reports of new polio outbreaks in some areas and their consequences have added to such concerns (4).

Global and regional attention to COVID-19 has meant the desire of health workers to implement routine vaccination programmes during this period, have been problematic. Limited health human resources, especially in low and middle-income countries due to their involvement with COVID-19, is one of the factors reducing immunization coverage in these countries (5). Despite UNICEF's efforts, it appears that restrictions on the transportation of vaccines to these countries, including restrictions on movement and items related to border crossings and airspace, are among the factors that could have contributed to this delay. Other contributing factors are the closure of schools in many parts of the world and the decline in vaccination coverage normally associated with routine deliveries in schools (6). Moreover, logistical obstacles (7) and the constraints created in relation to financial resources (8) have aggravated this situation. On top of this, many parents also express fear of being exposed to COVID-19 when their children want to be vaccinated (9).

In the context of the implementation of primary health care programmes for vaccination coverage in the
Eastern Mediterranean Region, it was decided in 1997 to attempt to eradicate measles by 2010. In 1981, the incidence of measles in the Region was 193 per 100000 , and by 2001 it was 6.8 per 100000 (10). Although specific programmes and solutions were proposed to achieve this goal (such as efforts to cover over 95\% of the first stage of the measles vaccine), this was not achieved by 2010 and was re-planned for 2015. Meanwhile, several major outbreaks occurred with a high incidence of the disease due to civil war and population displacement in countries such as Djibouti, Iraq, Somalia and South Sudan (11-14).

Vaccination coverage in these areas rose to $82 \%$ for the first dose of measles-containing vaccine $(\mathrm{MCV})$ in 2018 (compared to $79 \%$ in 2013), and MCV2 coverage rose from $59 \%$ in 2013 to $74 \%$ in 2018 . The incidence of measles has also dropped from 33.5 per million in 2013 to 23.3 per million in 2019. Despite this relative improvement, other major outbreaks of measles have occurred during this period. For example, in 2018, the incidence of measles increased to 91.2 per million people (15).

What is emerging today in the wake of vaccination problems in the Eastern Mediterranean Region is the concern that a new wave of measles outbreaks could occur, which could unfortunately be due to declining MCV1 and MCV2 vaccination coverage. Inevitably, important parts of recent primary health care activity, even in countries with a good track record in terms of primary health care (16), have shifted to COVID-19. Added to this, internal and international conflicts in the Region have meant that the lack of primary health care in areas such as mass immunization following the COVID-19 pandemic has raised serious concerns about the outbreak of controlled diseases.

In summary, it is important to inform populations about the need to conscientiously complete the vaccination process in the context of the COVID-19 pandemic. In addition, the needs of governments in the Region must be met in order to facilitate access to required vaccines for this goal. Finally, the effective provision of health service staff, and assistance from international health organizations in this regard, would be necessary and welcome. 


\section{References}

1. World Health Organization. WHO director-general's opening remarks at the media briefing on COVID-19. Geneva: World Health Organization; 1 May, 2020. (https://www.who.int/dg/speeches/detail/who-director-general-s-opening-remarks-at-the-media-briefing-on-covid-19---1-may-2020).

2. UNICEF. Despite Covid-19 pandemic, routine vaccination of children continues across the Middle East and North Africa. New York: UNICEF; 3 May 2020. (https://www.unicef.org/mena/press-releases/despite-covid-19-routine-vaccination-children-continues-middle-east-north-africa).

3. World Health Organization. At least 80 million children under one at risk of diseases such as diphtheria, measles and polio as COVID-19 disrupts routine vaccination efforts, warn Gavi, WHO and UNICEF. Geneva: World Health Organization; 22 May, 2020. (https://www.who.int/news-room/detail/22-05-2020-at-least-80-million-children-under-one-at-risk-of-diseases-such-asdiphtheria-measles-and-polio-as-covid-19-disrupts-routine-vaccination-efforts-warn-gavi-who-and-unicef).

4. UNICEF. Joint press statement: polio programme accelerates efforts to respond to new polio outbreaks in Sudan and Yemen. New York: UNICEF; 11 September, 2020. (https://www.unicef.org/mena/press-releases/joint-press-statement-polio-programme-accelerates-efforts-respond-new-polio).

5. Chandir S, Siddiqi DA, Mehmood M, Setayesh H, Siddique M, Mirza A, et al. Impact of COVID-19 pandemic response on uptake of routine immunizations in Sindh, Pakistan: an analysis of provincial electronic immunization registry data. Vaccine. 2020;38(45):7146-55.

6. McDonald HI, Tessier E, White JM, Woodruff M, Knowles C, Bates C, et al. Early impact of the coronavirus disease (COVID-19) pandemic and physical distancing measures on routine childhood vaccinations in England, January to April 2020. Eurosurveillance. 2020;25(19):2000848.

7. Abbas K, Procter SR, van Zandvoort K, Clark A, Funk S, Mengistu T, et al. Routine childhood immunisation during the COVID-19 pandemic in Africa: a benefit-risk analysis of health benefits versus excess risk of SARS-CoV-2 infection. Lancet Glob Health. 2020;8(10):e1264-e72.

8. Badrfam R, Zandifar A. Fighting COVID-19; Governments or the Masses? J Iran Med Council. 2021;3(4):211-213.

9. Saxena S, Skirrow H, Bedford H. Routine vaccination during covid-19 pandemic response. BMJ. 2020;369:m2392

10. Gaafar T, Moshni E, Lievano F. The challenge of achieving measles elimination in the Eastern Mediterranean Region by 2010. J Infect Dis. 2003;187(Supplement_1):S164-S71.

11. Teleb N, Lebo E, Ahmed H, Hossam AR, El Sayed ET, Dabbagh A, et al. Progress toward measles elimination-eastern mediterranean region, 2008-2012. Morb Mortal Wkly Rep. 2014;63(23):511.

12. Guha-Sapir D, Ratnayake R. Consequences of ongoing civil conflict in Somalia: evidence for public health responses. PLoS Med. 2009;6(8):e1000108.

13. Gambino C, Trevelyan EN, Fitzwater JT. Foreign-born population from Africa, 2008-2012: Washington, DC: US Department of Commerce, Economic and Statistics Administration; 2014.

14. Chatelard G. The politics of population movements in contemporary Iraq: A research agenda. Writing the Modern History of Iraq: Historiographical and Political Challenges: World Scientific. 2012:359-78. https://doi.org/10.1142/9789814390576_0022

15. Goodson JL. Progress Toward Measles Elimination-Eastern Mediterranean Region, 2013-2019. Morb Mortal Wkly Rep. 2020;69.

16. Badrfam R, Zandifar A. Coronavirus disease 2019 in Iran: the need for more attention to primary health care. Public Health. 2020;182:187. 